\title{
镍介导的苯酚衍生物碳氧键活化合成三氟甲基芳烃
}

\author{
王震宇 ${ }^{a}$ 戴辉雄 $*, a, b$ \\ ( ${ }^{a}$ 南京中医药大学新中药学院 南京 210023) \\ ( ${ }^{b}$ 中国科学院上海药物研究所 中国科学院受体研究重点实验室 上海 201203)
}

\section{Synthesis of Trifluoromethylarenes via Nickel-Mediated C-O Bond Activation of Phenol Derivatives}

\author{
Wang, Zhenyu ${ }^{a}$ \\ Dai, Huixiong $*, a, b$ \\ ( ${ }^{a}$ School of Chinese Materia Medica, Nanjing University of Chinese Medicine, Nanjing 210023) \\ ( ${ }^{b}$ Chinese Academy of Sciences Key Laboratory of Receptor Research, Shanghai Institute of \\ Materia Medica, Shanghai 201203)
}

三氟甲基芳烃在药物和农药中是一种非常重要的 结构单元(Scheme 1), 引入三氟甲基可以改善药物的体 内代谢稳定性、亲脂性和生物利用度 ${ }^{[1]}$. 目前过渡金属 介导和催化的三氟甲基化反应成为制备三氟甲基芳烃 的重要方法 ${ }^{[2]}$. 芳基卤化物因为其具有较高活性被作为 常用的亲电偶联试剂. 最近, 化学家们致力于拓宽亲电 偶联试剂范围, 寻找较为㤢性且储量丰富的试剂来替代 卤代物. 由于苯酚衍生物来源广泛, 其结构和电性易于 改变, 因此受到化学家的广泛关注. 迄今为止, 各种亲 核试剂，包括有机硼、有机锌、有机锂、胺和碳亲核试 剂已被用于苯酚衍生的亲电试剂的偶联反应 ${ }^{[3]}$. 然而, 苯酚衍生物作为亲电试剂与亲核三氟甲基化试剂的偶 联反应未见报道.<smiles>CNCCC(Oc1ccc(C(F)(F)F)cc1)c1ccccc1</smiles><smiles>O=C(O)c1cccnc1Nc1cccc(C(F)(F)F)c1</smiles>

Fluxetine<smiles>O=C1CCCC(=O)C1C(=O)c1ccc(C(F)(F)F)cc1[N+](=O)[O-]</smiles>

Nitisinione

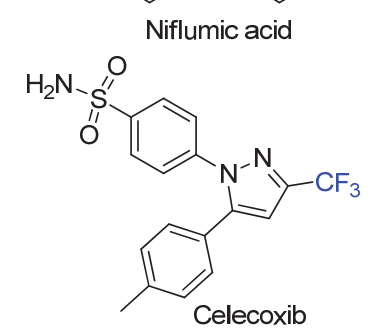

图式 1 芳基三氟甲基的药物

Scheme 1 Four trifluoromethylarene-containing drugs
镍作为含量丰富的金属, 被广泛应用于交叉偶联反 应，并能介导一些钯和铜难以构建的反应. 然而，相对 于钯和铜催化的三氟甲基化反应，镍促进的三氟甲基化 反应报道较少的. 2008 年, Vicic 小组 ${ }^{[4]}$ 报道了多种双磷 配体稳定的镍三氟甲基复合物(dippe) $\mathrm{Ni}(\mathrm{Ar})\left(\mathrm{CF}_{3}\right)$, 但是 这种复合物还原消除生成芳基三氟甲基化合物是不可 行的(Scheme 2a). 随后 Sanford 小组 ${ }^{[5]}$ 制备了三吡唑硼 酸盐的高价芳基三氟甲基镍复合物 $\mathrm{ArNi}^{\mathrm{IV}} \mathrm{CF}_{3} 、 \mathrm{ArNi}^{\mathrm{III}}$ $\mathrm{CF}_{3}$, 证明了高价的 $\mathrm{ArNiCF}_{3}$ 可以通过还原消除生成芳 基三氟甲基化合物(Scheme 2a). 最近, Nebra 小组 ${ }^{[6]}$ 和

(a) Vicic 2008

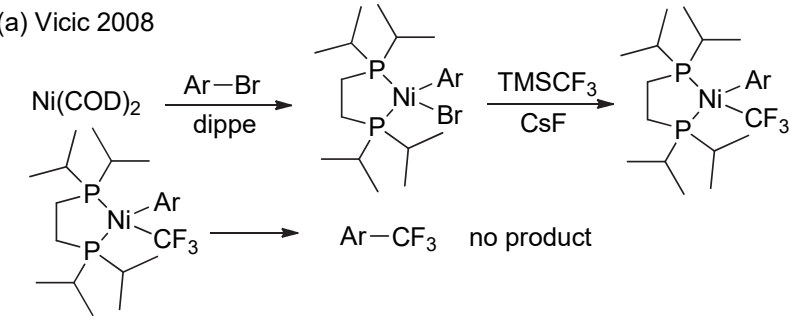

(b) Sanford 2015

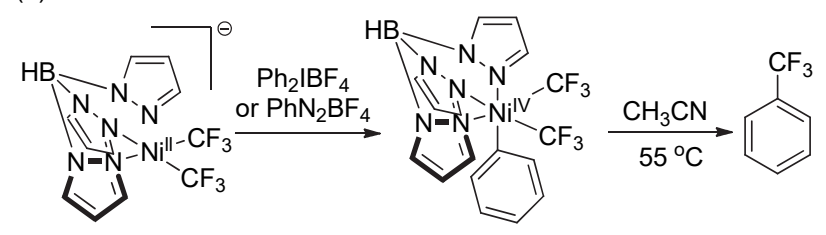

图式 2 镍介导的芳基三氟甲基化转金属与还原消除

Scheme 2 Nickel-mediated aryl trifluoromethylation transmetalation and reductive elimination

* Corresponding author. E-mail: hxdai@simm.ac.cn. Published online October 3, 2020. 
Sanford 小组 ${ }^{[7]}$ 分别报道了镍介导和镍催化的芳烃的三 氟甲基化反应.

基于以上研究, 中国科学院上海有机化学研究所有 机氟化学重点实验室卿风领课题组 ${ }^{[8]}$ 报道了首例镍介导 的苯酚衍生物 $\mathrm{C}-\mathrm{O}$ 键活三氟甲基化 (Scheme 3). 首先, 作者对转金属过程进行了深入研究, 发现四甲基氟化铵 和外加三甲基磷可以促进转金属过程，几乎定量地得到 磷配体稳定的芳基镍三氟甲基络合物. 随后作者对还原 消除过程进行了考察, 发现了一种独特温和的氧化剂 $\mathrm{CCl}_{3} \mathrm{CN}$ 能够将镍氧化至高价态, 从而发生还原消除得 到芳基三氟甲基化合物. 在得到最佳条件后，作者对反 应底物的普适性进行了考察, 无论是吸电子、供电子的 苯酚衍生物都能以中等以上的收率得到目标产物. 杂环 类底物也可以中等以上的收率得到目标化合物. 此外, 作者进一步探究了反应的合成应用，成功实现了保护的 酪氨酸、雌酚酮、双酚芴、山姜素、刺芒柄花素、喜树 碱、胺碘酮、非诺贝特中 $\mathrm{C}-\mathrm{O}$ 键的三氟甲基化反应 (Scheme 4). 值得注意的是, 作者对反应条件稍加修改 后2-荎甲腈, 芳基硫酯也可以通过这种策略实现三氟甲 基化，得到相应的芳基三氟甲基化合物.
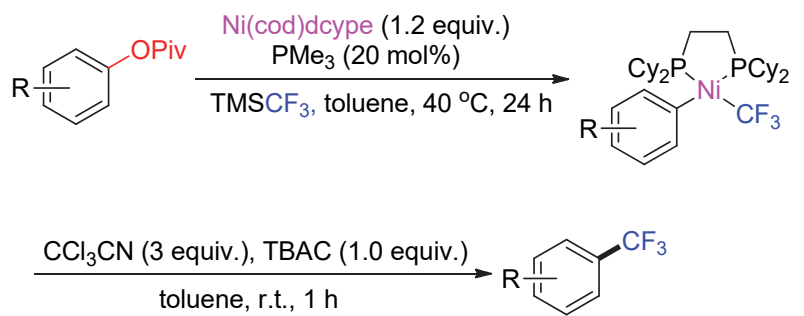

图式 3 镍介导的苯酚衍生物的三氟甲基化反应 Scheme 3 Nickel-mediated trifluoromethylation of phenol derivatives

总之, 卿凤翎课题组开发了一种新型的镍介导的三 氟甲基化反应，可以将廉价易得的苯酚衍生物转化为芳 基三氟甲基化合物。该反应条件温和，底物适应性广， 为生物活性分子和药物分子中三氟甲基的引入提供了 方便可行的策略.<smiles>COC(=O)NC(Cc1ccc(C(F)(F)F)cc1)C(=O)OC</smiles>

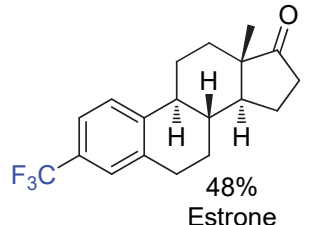<smiles>CC(C)(F)c1ccc(C2(c3ccc(C(F)(F)F)cc3)c3ccccc3-c3ccccc32)cc1</smiles>
Bisphenol FL<smiles>COc1cc(C(F)(F)F)cc2c1C(=O)CC(c1ccccc1)O2</smiles><smiles>COc1ccc(-c2coc3cc(C(F)(F)F)ccc3c2=O)cc1</smiles><smiles>CC[C@]1(OC(F)(F)F)C(=O)OCc2c1cc1n(c2=O)Cc2cc3cc(C(F)(F)F)ccc3nc2-1</smiles><smiles>CCCCc1oc2ccccc2c1C(=O)c1ccc(C(F)(F)F)cc1</smiles>

图式 4 复杂分子的后期修饰

Scheme 4 Late stage modification of complex molecules

\section{References}

[1] Cametti, M.; Crouse, B.; Metrangolo, P.; Milani, R.; Resnati, G Chem. Soc. Rev. 2012,41, 31

[2] Alonso, C.; Marigorta, E. M.; Rubiales, G.; Palacios, F. Chem. Rev 2015, 115,1847

[3] Zeng, H. Y.; Qiu, Z. H.; Chen, Z. W.; Li, C. J. ACS Catal. 2017, 7, 510.

[4] Dubinina, G. G.; Brennessel, W. W.; Miller, J. L.; Vicic, D. A. Organometallics 2008, 27, 3933.

[5] Bour, J. R.; Camasso, N. M.; Sanford, M. S. J. Am. Chem. Soc. 2015, 137, 8034

[6] Accriscio, F. D.; Borja, P.; Merceron, N. S.; Boutignon, M. F.; Mezailles, N.; Nebra, N. Angew. Chem., Int. Ed. 2017, 56, 12898.

[7] Meucci, E. A.; Nguyen, S. N.; Camasso, N. M.; Chong, E.; Afiafard, A.; Canty, A. J.; Sanford, M. S. J. Am. Chem. Soc. 2019, 141,12872 .

[8] Hu, W, Q.; Pan, S.; Xu, X, H.; Vicic, D. A.; Qing, F, L. Angew. Chem. Int. Ed. 2020, 59, 16076. 